\title{
Regulation of host immune cells and cytokine production induced by Trichinella spiralis infection
}

\author{
Yining Song ${ }^{1, a}$, Jing $\mathrm{Xu}^{1, \mathrm{a}}$, Xuelin Wang ${ }^{2, a}$, Yong Yang ${ }^{2}, \mathrm{Xue} \mathrm{Bai}^{2}$, Jianda Pang ${ }^{1,2}$, Xinrui Wang ${ }^{1}$, Mingchuan Yu ${ }^{1}$, \\ Mingyuan $\mathrm{Liu}^{2,3, *}$, Xiaolei Liu ${ }^{2, *}$, and Shumin Sun ${ }^{1,2, *}$ \\ ${ }^{1}$ College of Animal Science and Technology, Inner Mongolia University for Nationalities, Inner Mongolia, 028042 Tongliao, PR China \\ ${ }^{2}$ Key Laboratory of Zoonosis Research, Ministry of Education, Institute of Zoonosis/College of Veterinary Medicine, Jilin University, \\ 130000 Changchun, PR China \\ 3 Jiangsu Co-Innovation Center for Prevention and Control of Important Animal Infectious Diseases and Zoonoses, Yangzhou, Jiangsu, \\ PR China
}

Received 19 July 2019, Accepted 5 December 2019, Published online 19 December 2019

\begin{abstract}
The nematode Trichinella spiralis can cause immunoregulation during the early phase of infection. However, previous studies are still insufficient for a full understanding of this phenomenon and its underlying mechanism. In this study, immune cells and cytokine profiles of $T$. spiralis infected mice were examined by Meso Scale Discovery (MSD) and flow cytometry. The MSD results of the spleen showed that Th1 immunity was inhibited from $6 \mathrm{~h}$ to 6 days post-infection (dpi) and the level of Th2 immune response was significantly increased at 6 dpi. The mesenteric lymph node showed a Th1/Th2 mixed immune response from 3 dpi to 6 dpi with a downtrend of Th1 at 6 dpi. Flow cytometry analysis showed that the proportion of Th1 cells of T cells was decreased significantly at $6 \mathrm{~h}$ after infection, the proportion of Th2 cells was markedly increased, indicating that Th1 immunity was significantly inhibited at $6 \mathrm{~h}$ after infection, and a hybrid immune response based on Th2 type was presented from $30 \mathrm{~h}$ to 6 dpi. The immunoregulation effects observed during this study have provided a better understanding of the development of the immune response induced by Trichinella infection.
\end{abstract}

Key words: Trichinella spiralis, Meso Scale Discovery, Cytokines, Immunoregulation.

Résumé - Régulation de la production des cellules immunitaires de l'hôte et des cytokines induite par l'infection par Trichinella spiralis. Le nématode Trichinella spiralis peut provoquer une immunorégulation pendant la phase précoce de l'infection. Cependant, les études précédentes sont encore insuffisantes pour bien comprendre ce phénomène et son mécanisme sous-jacent. Dans cette étude, les profils de cellules immunitaires et de cytokines de souris infectées par T. spiralis ont été examinés par DMÉ (Découverte à Méso-Échelle) et cytométrie de flux. Les résultats DMÉ de la rate ont montré que l'immunité Th1 était inhibée $6 \mathrm{~h}$ à 6 jours après l'infection (jai) et que le niveau de réponse immunitaire Th2 était augmenté de manière significative à 6 jai. Le ganglion mésentérique présentait une réponse immunitaire mixte Th1/Th2 de 3 à 6 jai avec une tendance à la baisse de Th1 à 6 jai. L'analyse par cytométrie en flux a montré que la proportion de lymphocytes $\mathrm{T}$ Th1 était significativement réduite $6 \mathrm{~h}$ après l'infection, que la proportion de Th2 était nettement augmentée, ce qui indiquait que l'immunité Th1 était significativement inhibée $6 \mathrm{~h}$ après l'infection, et qu'une réponse immunitaire hybride sur le type Th2 était présentée de $30 \mathrm{~h}$ à 6 jai. Les effets d'immunorégulation observés au cours de cette étude ont permis de mieux comprendre le développement de la réponse immunitaire induite par l'infection à Trichinella.

\section{Introduction}

Trichinellosis is a common zoonosis with a global distribution that has a great socioeconomic impact on human and animal health [12]. Although Trichinella spiralis is well controlled in Europe and the United States, it is still prevalent in developing and developed countries, including China,
Argentina, and Eastern Europe [10]. After its successful isolation in 1835 [4], there has been a large number of studies on T. spiralis infection and parasitism [19]. It has been found that T. spiralis invasion is not just a simple case of mechanical penetration [23], and that immune suppression has been observed in the intestinal phase of mice [20,21]. Continuous infection with $T$. spiralis can stimulate the body to produce

*Corresponding authors: Iiumy36@163.com, Iiuxlei@163.com, shums1975@163.com

${ }^{\text {a }}$ These authors contributed equally to this work.

This is an Open Access article distributed under the terms of the Creative Commons Attribution License (https://creativecommons.org/licenses/by/4.0), which permits unrestricted use, distribution, and reproduction in any medium, provided the original work is properly cited. 
acquired immune effects, but the host cannot completely inhibit the growth of $T$. spiralis, indicating that it can inhibit, and escape from, the host's immune response [8]. This phenomenon further supports this study that the host's immune mechanisms play an important role in the development, invasion, and parasitism of $T$. spiralis [26].

During the early stage of $T$. spiralis infection, cellular immunity is inhibited, while in the late stage, cellular immune function has recovered, and humoral immunity began to play a role in resisting $T$. spiralis infection [1]. During $T$. spiralis infection, Th1/Th2 cells play an important role in balancing immune system function, and once that balance is broken, the host will become infected [17]. Numerous studies have shown that $T$. spiralis infection affects its host's immune system, inhibiting Th1/Th17 cell response and inducing Treg cells to reduce the inflammatory response [28]. When T. spiralis infects the host, different phase specific antigens are produced in different developmental stages of the parasite life cycle, which induce the host to produce a specific immune response [25, 27]. To account for this characteristic, we have carried out experiments to verify the four key stages of $T$. spiralis infection during the intestinal phase. By examining the expression and regulation of host immune cells and cytokines, our goal is to find a breakthrough point in the immune regulation of $T$. spiralis which could lead to new approaches to the treatment of trichinellosis.

\section{Materials and methods Ethics}

All mice protocols were reviewed and approved by the Ethics Committee of Jilin University affiliated with the Provincial Animal Health Committee, Jilin Province, China (Ethical Clearance number IZ- 2009-08).

\section{Obtaining of muscle larvae and infection of BALB/c mice}

Trichinella spiralis (ISS534) was provided by the Institute of Zoonosis of Jilin University. Female BALB/c mice, aged 6 weeks, were purchased from the Animal center of the medical department of Jilin University.

Muscle larvae were obtained from infected mice by artificial digestion performed using the latest version of the magnetic stirrer protocol, according to the OIE standard protocol. After a series of precipitation and washing steps, muscle larvae suitable for sample addition were finally obtained. The number of $T$. spiralis larvae obtained by digestion was counted under a microscope.

Forty-eight BALB/c mice were divided randomly into two groups, an infected group and a control group. Each mouse in the infected group was infected with 250 muscle larvae at the same time. Under aseptic conditions, samples of peripheral blood, spleens, and mesenteric lymph nodes of the infected group and the control group (six mice per group) were collected for MSD and flow cytometry analysis at $6 \mathrm{~h}, 30 \mathrm{~h}, 3 \mathrm{~d}$, and $6 \mathrm{~d}$ after infection.

\section{Meso scale discovery (MSD) determination of cytokines}

Based on the following advantages, MSD technology was selected for this experiment. Since the sensitivity of MSD is up to $0.05 \mathrm{pg} / \mathrm{mL}$, it is more effective in finding a difference between the infected group and the control group. Only when the MSD plate is fed into the instrument and stimulated by electrodes can the signal be generated. The excitation time of each well is unified with the signal acquisition time, and the stability of data can be high.

The mesenteric lymph nodes and spleens were obtained at 6 h, 30 h, 3 dpi, and 6 dpi from the infected and control mice, under aseptic conditions, and stored at $-80{ }^{\circ} \mathrm{C}$ prior to use in the detection of cytokines IL-2, IL-4, IL-10, IL-17A, IFN- $\gamma$, and TGF- $\beta$. For the cytokine determination test, $300 \mu \mathrm{L}$ of linker was added to $200 \mu \mathrm{L}$ of biomarker antibody (K15069L-1, Univ. Biotechnology, China) and incubated for $30 \mathrm{~min}$ at room temperature, then $200 \mu \mathrm{L}$ of termination solution was added and the solution incubated at room temperature for $30 \mathrm{~min}$. A volume of $50 \mu \mathrm{L}$ of antibody was added to each well of the MSD plate and the plate was incubated for $1 \mathrm{~h}$ at room temperature. The MSD plate was rinsed three times with $1 \times$ PBS $(0.05 \%$ Tween-20), and $25 \mu \mathrm{L}$ each of the diluent and sample were added. The plate was sealed and shaken at room temperature for $1 \mathrm{~h}$. After washing the MSD plate three times again, $50 \mu \mathrm{L}$ of the detection antibody was added to each well, and the plate shaken at room temperature for $1 \mathrm{~h}$. After incubation, the MSD plate was rinsed three times with $150 \mu \mathrm{L}$ of washing solution. The MSD plate was rinsed three times, $150 \mu \mathrm{L}$ of the readout liquid was added. All data were analyzed with MSD software (QuickPlex SQ120, MSD, USA).

\section{Flow cytometry analysis of Th1, Th2, Th17, and Treg cells}

An amount of $100 \mu \mathrm{L}$ of peripheral blood was taken at $6 \mathrm{~h}$, $30 \mathrm{~h}, 3 \mathrm{dpi}$, and $6 \mathrm{dpi}$ from 12 mice from the infected and control mice, under aseptic conditions, and placed in an anticoagulant tube prior to further tests. Th1 cells $\left(\mathrm{CD}^{+}, \mathrm{CD}^{+}\right.$, IFN- $\left.\gamma^{+}\right)$, Th2 cells $\left(\mathrm{CD}^{+}, \mathrm{CD}^{+}, \mathrm{IL}-4^{+}\right)$, Th17 cells $\left(\mathrm{CD}^{+}\right.$, $\left.\mathrm{CD} 4^{+}, \mathrm{IL}-17^{+}\right)$, and Treg cells $\left(\mathrm{CD} 4^{+}, \mathrm{CD} 25^{+}, \mathrm{Foxp}^{+}\right)$were analyzed and identified. The cellular subpopulations were detected using fluorescently labelled antibodies with samples incubated for $15 \mathrm{~min}$. All the steps were carried out at 2-8 ${ }^{\circ} \mathrm{C}$. The FITC anti-mouse CD4 antibody (No. 11-004281 , Biolegend, USA) was used on all samples. Cy5 anti-mouse CD3 antibody (No. 15-0031-82, eBioscience, USA) and PE anti-mouse IFN- $\gamma$ antibody (No. 12-7311-81, eBioscience, USA) to label Th1 cells; Cy5 anti-mouse CD3 antibody (No. 15-0031-82, eBioscience, USA) and APC anti-mouse IL-4 antibody (No. 17-7041-81, eBioscience, USA) to label Th2 cells; Cy5 anti-mouse CD3 antibody (No. 15-0031-82, eBioscience, USA) and PE anti-mouse IL-17 antibody (No. 12-7177-81, eBioscience, USA) to label Th17 cells; and APC anti-mouse CD25 antibody (No. 17-0251-81, eBioscience, USA) and PE anti-mouse Foxp3 antibody (No. 135773-82, eBioscience, USA) to label Treg cells. All data were 


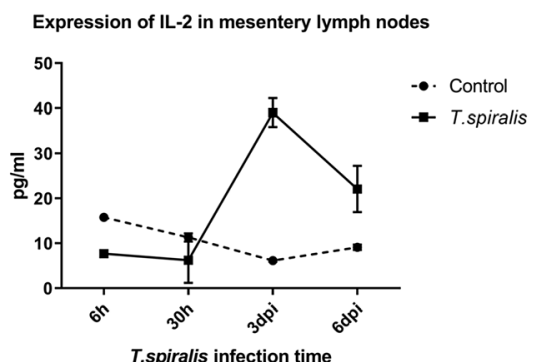

Expression of IL-17A in mesentery lymph nodes

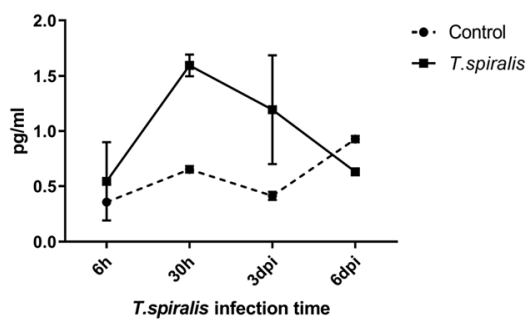

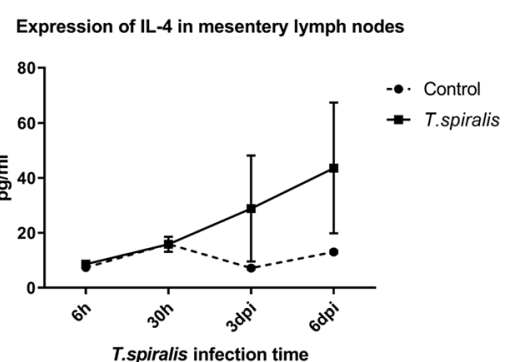

Expression of IFN-y in mesentery lymph nodes

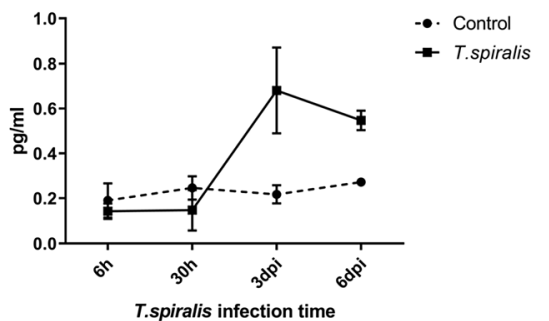

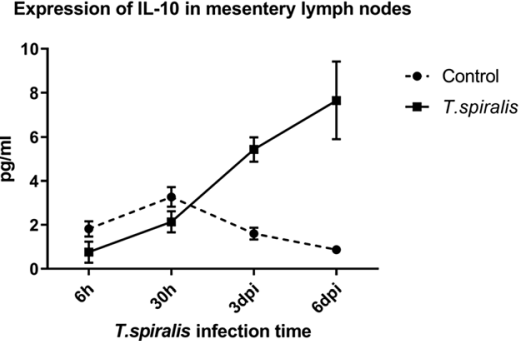

Expression of TGF- $\beta$ in mesentery lymph nodes

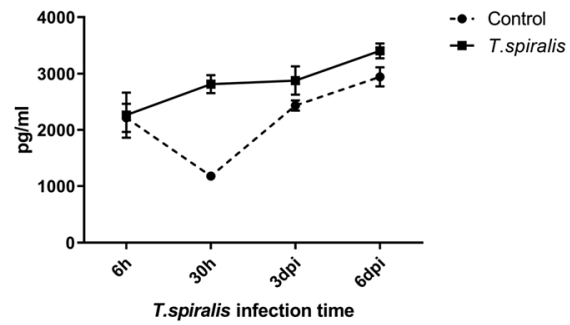

Figure 1. Cytokine expression levels of IL-2, IL-4, IL-10, IL-17A, IFN- $\gamma$, and TGF- $\beta$ in the mesentery lymph nodes in mice infected with 250 muscle larvae of Trichinella spiralis.

analyzed using the CellQuest software on the BD FACSCalibur flow cytometer (BD Biosciences, Heidelberg, Germany).

\section{Data processing and statistical analysis}

Data differences were analyzed by ordinary one-way ANOVA with GraphPad Prism 8.1.2 software. $p<0.05$ was considered to be statistically significant. The replications of the experiments (MSD and flow cytometry) were performed three times.

\section{Results}

\section{MSD detection of cytokine results}

When compared with the control group, the following observations were made in the mesenteric lymph nodes of infected mice. IL-2 levels significantly decreased at $6 \mathrm{~h}$ after infection, increased significantly at 3-6 dpi, and were not significantly different at $30 \mathrm{~h}$; IL-4 levels were increased from 3 dpi to 6 dpi. IL-10 levels decreased (albeit not significantly) at $6 \mathrm{~h}$ and $30 \mathrm{~h}$ after infection, and increased significantly at 3-6 dpi, and IL-17A levels decreased significantly at $6 \mathrm{dpi}$, and significantly increased at $30 \mathrm{~h}$ and $3 \mathrm{dpi}$. IFN- $\gamma$ levels were significantly increased at 3-6 dpi, and TGF- $\beta$ levels were increased at $30 \mathrm{~h}$ after infection (Fig. 1).

When compared with the control group, the following observations were made in the spleens of infected mice: levels of IL-2 were significantly decreased at $6 \mathrm{~h}, 30 \mathrm{~h}$, and $3 \mathrm{~d}$ after infection, IL-4 levels were significantly decreased at $6 \mathrm{~h}$ after infection and increased at $6 \mathrm{dpi}$, and IL-10 levels were significantly decreased at $30 \mathrm{~h}$ and $3 \mathrm{~d}$ after infection. IFN- $\gamma$ levels were decreased at $30 \mathrm{~h}$ after infection and TGF- $\beta$ levels were decreased at 3 dpi, significantly increased at $6 \mathrm{~h}$, and slightly increased at 6 dpi (Fig. 2).

\section{Flow cytometry analysis results}

\section{Evaluation of the percent change of T lymphocytes}

The ratio of $\mathrm{CD}^{+} / \mathrm{CD}^{+}$reflects the immune regulation status and immune level of the host. In infected mice at the intestinal stage of infection, levels of $\mathrm{CD}^{+} \mathrm{T}$ cells at 6 dpi were markedly increased, while $\mathrm{CD}^{+} \mathrm{T}$ cells at $6 \mathrm{dpi}$ were decreased. According to the trends, CD4+ T levels were decreasing at $30 \mathrm{~h}$ after infection, while $\mathrm{CD} 8+\mathrm{T}$ levels were on the rise (Fig. 3A and B). Compared with the ratio of $\mathrm{CD} 4^{+} / \mathrm{CD}^{+}$at $6 \mathrm{~h}$, it was significantly decreased at $30 \mathrm{~h}$ after infection (Fig. 3C).

\section{Evaluation of the percent change of IFN- $\gamma$ detection}

As far as the overall trend is concerned, the expression level of IFN- $\gamma$ was fluctuated. The secretion of IFN- $\gamma$ by Th1 cells is involved in cellular immune regulation, mediates the immune response, and has an immunosuppressive effect on the worms invading the intestine of mice. In the infected group, the expression of IFN- $\gamma$ at $6 \mathrm{~h}$ was significantly lower, while at $30 \mathrm{~h}$, it was slightly higher (Fig. 4). Compared with the $6 \mathrm{~h}$ infection group, the expression of IFN- $\gamma$ in the infected group was significantly increased at $6 \mathrm{dpi}$.

\section{Evaluation of the percent change of IL-17}

IL-17 mediates the inflammatory response. Expression in the infected group was gradually elevated at the four time points of infection (Fig. 5). Compared with the $6 \mathrm{~h}$ infection group, the expression of IL-17 in the infected group was increased at 6 dpi.

\section{Evaluation of the percent change of Foxp3 ${ }^{+}$}

Foxp $3^{+}$was expressed at a high level at each time point (Fig. 6). The infected group expression levels were only higher 

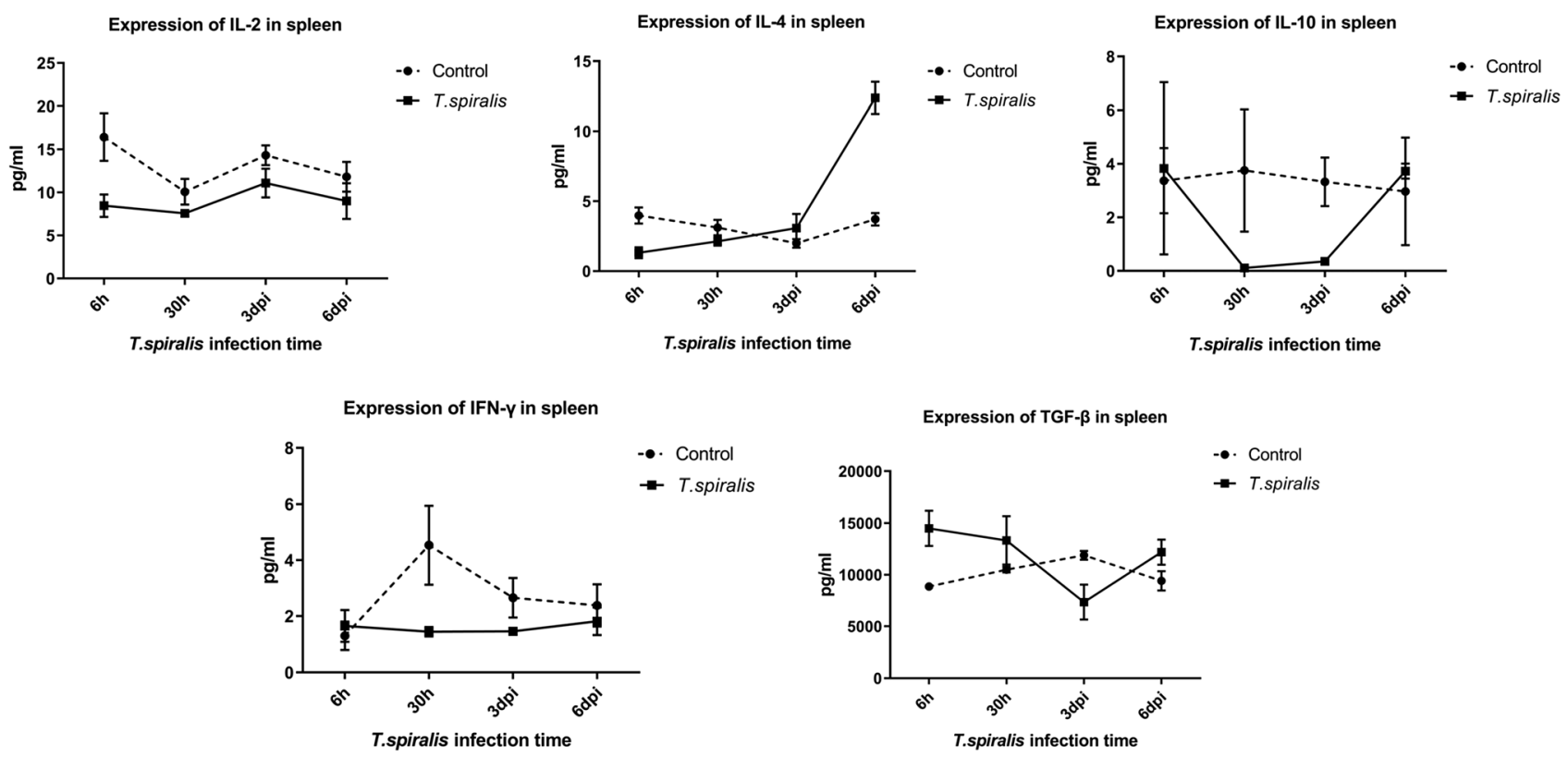

Figure 2. Cytokine expression levels of IL-2, IL-4, IL-10, IFN- $\gamma$, and TGF- $\beta$ in the spleen in mice infected with 250 muscle larvae of Trichinella spiralis.

A

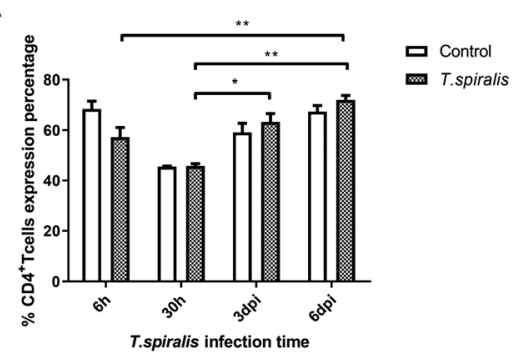

B

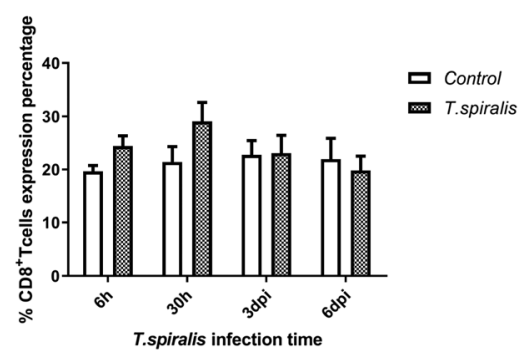

C

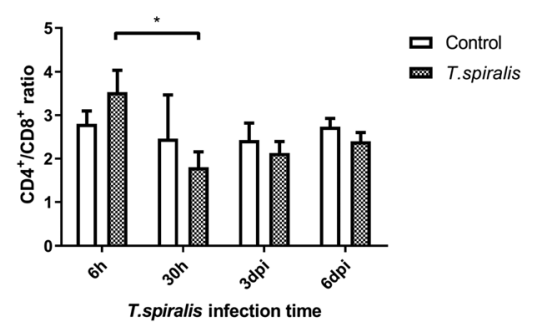

Figure 3. Percentage and expression levels of CD4+ and CD8+ $\mathrm{T}$ cells in mice infected with 250 muscle larvae of Trichinella spiralis compared to uninfected (control) mice from $6 \mathrm{~h}$ to $6 \mathrm{dpi}$. (A) Comparison of the mean percentage $( \pm \mathrm{SD})$ of CD4 ${ }^{+} \mathrm{T}$ cells. (B) Comparison of the mean percentage $( \pm \mathrm{SD})$ of $\mathrm{CD} 8^{+} \mathrm{T}$ cells. (C) Comparison of the expression $( \pm \mathrm{SD})$ of $\mathrm{CD}^{+} / \mathrm{CD} 8^{+} \mathrm{T}$ cells. ${ }^{*} p<0.05$ and $* * p<0.01$ indicating a statistically significant difference.

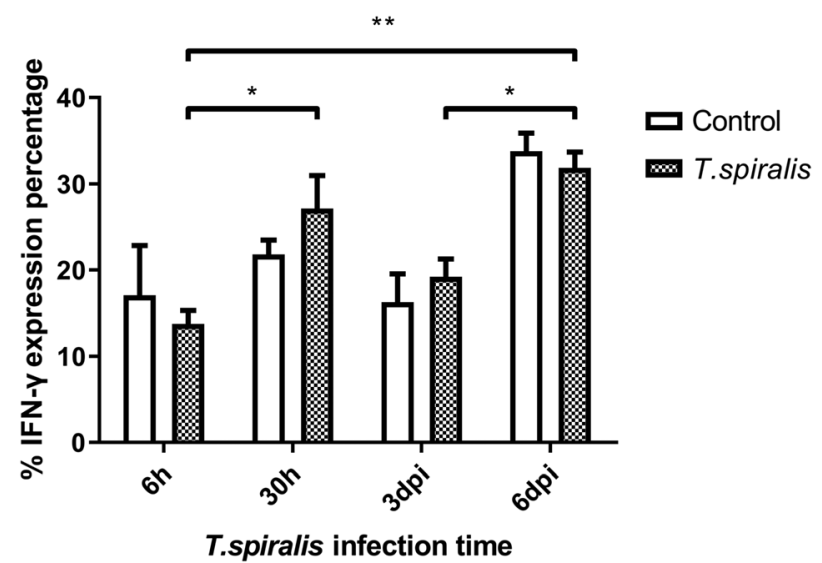

Figure 4. Percentage and expression levels of IFN- $\gamma$ of Th1 cells in mice infected with 250 muscle larvae of Trichinella spiralis compared to uninfected (control) mice from 6 h to $6 \mathrm{dpi}$. $* p<0.05$ and $* * p<0.01$ indicating a statistically significant difference.

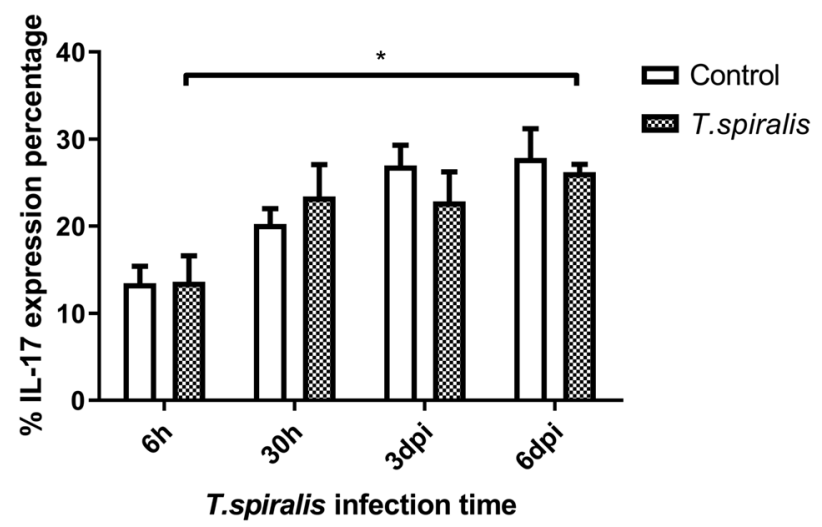

Figure 5. Percentage and expression of IL-17 of Th17 cells in mice infected with 250 muscle larvae of Trichinella spiralis compared to uninfected (control) mice from 6 h to 6 dpi. $* p<0.05$ indicating a statistically significant difference. 


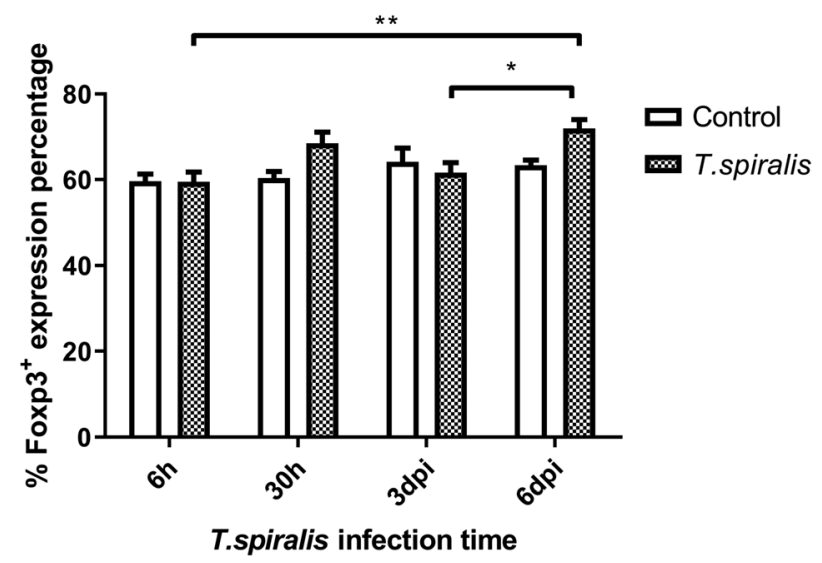

Figure 6. Percentage and expression levels of Foxp $3^{+}$of Treg cells in mice infected with 250 muscle larvae of Trichinella spiralis compared to uninfected (control) mice from 6 h to 6 dpi. * $p<0.05$ and $* * p<0.01$ indicating a statistically significant difference.

at $30 \mathrm{~h}$ and $6 \mathrm{dpi}$, and no significant differences were seen at the other two time points. Treg cell numbers were highest at $6 \mathrm{dpi}$.

\section{Evaluation of the percent change of IL-4}

Compared with the $30 \mathrm{~h}$ infection group, the expression of IL-4 in the infected group was significantly increased at 6 dpi. With regards to the overall trend, levels of IL-4 expression fluctuated greatly at $6 \mathrm{~h}$ and $3 \mathrm{dpi}$ (Fig. 7). IL-4 activates mast cells to release histamine and serotonin to increase intestinal peristalsis and causes diarrhea, thereby stimulating the discharge of parasites. Changes in IL-4 levels during intestinal invasion may be due to immune escape by $T$. spiralis.

\section{Discussion}

Trichinella spiralis infection has an immunosuppressive effect on the host's innate immune system [2, 24, 29]. At this stage, the worms develop rapidly, the morphology, and excretion change constantly, and the newborn larvae begin to be developed at 4 dpi. Ultimately, through complex developmental processes, the newborn larvae migrate rapidly with blood or lymph and invade the skeletal muscle. It is speculated that the immune regulation of the host at different time points up to $6 \mathrm{dpi}$ is complex and volatile. Most studies have tested the immune regulation above $1 \mathrm{dpi}$. In this study, different views on this detection time were presented, and mice were used as experimental animals to detect the immune response of mesenteric lymph nodes and spleen during the four stages. The four stages were: the invasion period of muscle larvae into intestinal epithelial cells infected with $T$. spiralis $(6 \mathrm{~h})$, the initial stage of adult $T$. spiralis $(30 \mathrm{~h})$, the mating period of the adult males and females $(3 \mathrm{dpi})$, and the growth period of newborn larvae (6 dpi).

The results of our MSD study showed the inflammatory reaction of the intestinal tract during $T$. spiralis infection from $6 \mathrm{~h}$ to $6 \mathrm{dpi}$. Expression of IL-2, important for inducing the Th1 response, was decreased significantly, the levels of TGF- $\beta$ and IL-17A increased significantly at $30 \mathrm{~h}$ after infection.

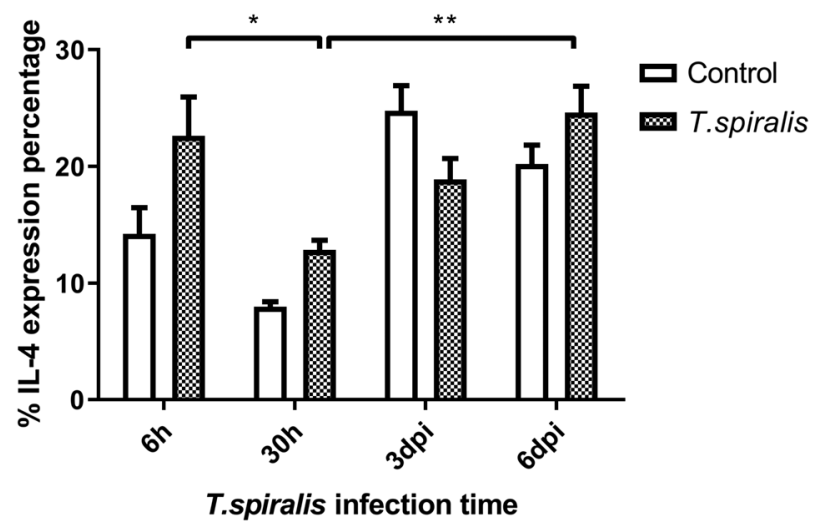

Figure 7. Percentage and expression of IL- 4 of Th2 cells in mice infected with 250 muscle larvae of Trichinella spiralis compared to uninfected (control) mice from 6 h to 6 dpi. ${ }^{*} p<0.05$ and ${ }^{* *} p<0.01$ indicating a statistically significant difference.

IL-17A is a pro-inflammatory cytokine that can strongly recruit neutrophils, suggesting that the host was in a state of pro-inflammatory reaction. The levels of Th1 cytokines (IL-2, IFN- $\gamma^{+}$) and Th2 cytokines (IL-4, IL-10) were significantly increased at both $3 \mathrm{dpi}$ and $6 \mathrm{dpi}$, suggesting that the host is in an inflammatory response stage, as shown by a mixed Th1/Th2 immune response. This is similar to the findings of Ilic et al. [16]. It was found that Th1 inflammation could effectively clear the intracellular infection. Trichinella spiralis had invaded mesenteric epithelial cells within $6 \mathrm{~h}$ after infection and had molted four times and developed into adults at $30 \mathrm{~h}$ after infection. Therefore, the inflammatory reaction at $30 \mathrm{~h}$ after infection could not completely eliminate all adult worms, which is in accordance with the characteristics of $T$. spiralis [14]. During the larval stage of $T$. spiralis development, the host is in a Th2-type immune response for a long period of time as a result of the long-term stimulation of the host immune system during the different developmental stages of the worm. Trichinella infection stimulates the host organism causing immune imbalance which gradually leads to a Th2-type immune response $[6,22]$. This response has helped find new treatments to diseases caused by Th1-type immune response imbalance, since Trichinella infection can regulate the immune balance of hosts with imbalances (e.g., patients with inflammatory bowel disease).

The MSD results of the spleen in the early stages of $T$. spiralis infection showed that the Th1 immune response was inhibited from $6 \mathrm{~h}$ after infection to $3 \mathrm{dpi}$, until it returned to normal levels at $6 \mathrm{dpi}$, whereas the immunosuppression of the Th2 response only occurred at $6 \mathrm{~h}$ after infection. In addition, the level of Th2 immune response induced by IL-4 was significantly increased in the spleen at $6 \mathrm{dpi}$, which was beneficial to the stimulation of the humoral immune response. In 1198, Lawrence et al. [17] have also found that intestinal lesions are related to IL-4 and the immune response mediated by Th 2 cells, agreeing with our results. These results suggest that the excreta of $T$. spiralis play an immunosuppressive role in peripheral immune organs (mesenteric lymph nodes and spleen). Th1 cells have an important role in the resistance to intracellular pathogens (viruses, bacteria, and parasites) and in 
the case of intracellular infection, Th1 cells can effectively trigger a cellular immune-mediated host defense response. However, the muscle larvae are still able to invade the intestinal epithelial cells and develop into adult parasites. Inhibition of Th1-type immunity in this period will provide sufficient time for the invasion, development, and the production of larvae of $T$. spiralis. It is beneficial therefore, for $T$. spiralis to establish infection [14, 22], evade the host immune system, and to reduce the resistance of the host and obtain the chance of parasite parasitism [6]. The level of immunosuppressive TGF- $\beta$ expression in the spleen was significantly increased at the $6 \mathrm{~h}$ after infection, indicating that it plays an important role in inducing Th1-type and Th2-type immunosuppression. This suggests that there must be some molecules in the excreta of $T$. spiralis that have a strong immunomodulatory effect that can stimulate the expression of TGF- $\beta$ [13]. Isolation and identification of these molecules will be part of a future study.

The immune mechanism of parasitic diseases mainly involves the interaction of Th1 and Th2 reactions and related cytokines, which inhibits their reproduction and amplification [11]. Th1 cells mainly secrete IFN- $\gamma$ to regulate cellular immunity and mediate cellular immune response. According to the results of this experiment, the expression of IFN- $\gamma$ fluctuates at different infection times, which indicates that the content of IFN- $\gamma$ secreted by Th1 cells changes, participates in the regulation of cellular immunity, mediates the immune response, and regulates cellular immunity, and invasiveness. Trichinella spiralis infecting the intestinal tract of mice has certain immunosuppressive effects. IL-4 produced by the Th2 subgroup mainly acts as an immune response against extracellular multicellular parasites. Mast cells are activated by IL-4 to release histamine and serotonin, which can increase intestinal peristalsis and diarrhea and stimulate the discharge of parasites. As a whole, the level of IL-4 fluctuates greatly at $30 \mathrm{~h}$ and $6 \mathrm{dpi}$, the changes may be caused by immune escape of T. spiralis. Th17 cells are one of the subgroup cells differentiated from CD4+ T cells, which specifically secrete cytokine IL-17. Even though Th17 cells complete differentiation, they will be limited by many complex factors. The differentiation of Th17 cells was inhibited by the production of IFN- $\gamma$ and IL-4, which were secreted by Th1 and Th2 cells [7]. In this experiment, the level of IL-17 in the infected group increased at $6 \mathrm{dpi}$ compared with $6 \mathrm{~h}$, indicating that Th17 secreted IL-17 to control infection. The number of Th17 and Treg cells would remain at a stable level to maintain the stability of the immune system. Trichinella spiralis most likely down-regulates host immune response through signaling to increase the number of Treg cells [16]. Many studies have shown that both the rapid and slow stages of Trichinella infection can increase the number of Treg cells. The experimental results support this statement, Foxp $3^{+}$was expressed at a high level at each time point. The main effect of Foxp $3^{+}$on host immune suppression is to maintain immune tolerance and control excessive inflammatory reactions $[5,15]$. In this study, we found that the mesenteric lymph nodes in mice after Trichinella infection showed a significant Th1/Th2 mixed immune response from 3 dpi, and before this time, $T$. spiralis had already established infection and developed into adulthood. The inflammatory and immune responses after 3 dpi helped to reduce the damage caused by parasites and establish long-term parasitism. The level of Th2 response in the spleen from 6 dpi was also significantly increased, which was consistent with published studies on $T$. spiralis immunology which show that infection induces a Th2-type-dominated immune response in the host [3, 18]. This reflects the complexity of host immune regulation in the early stages of Trichinella infection. Trichinella has achieved longterm parasitism in the host by inducing a Th2-type immune response produced by the body [9]. The results of this study will help to elucidate the immunosuppressive mechanism induced by $T$. spiralis in early induction of the host, and provide a firm foundation for the study of related diseases.

\section{Conflict of interest}

No financial or personal relationships are maintained with other authors or organizations that could inappropriately influence or bias this paper entitled "Regulation of host immune cells and cytokine production induced by Trichinella spiralis infection".

Acknowledgements. This study was supported by the National Key Research and Development Program of China (2017YFD0501300, 2017YFC1601202, 2016YFD0500707); the National Natural Science Foundation of China (NSFC 31520103916, 31872467, 31160504, 31460658); the Postdoctoral Science Foundation Project of China (2012M520674); the Inner Mongolia Provincial Natural Science Foundation (2017MS0321, 2011MS0404); and the Inner Mongolia University for Nationalities Postgraduate Research and Innovation Project (NMDSS173, NMDSS1861).

\section{References}

1. Alegre ML, Shiels H, Thompson CB, Gajewski TF. 1998. Expression and function of CTLA-4 in Th1 and Th2 cells. Journal of Immunology, 161, 3347-3356.

2. Bai X, Wu X, Wang X, Guan Z, Gao F, Yu J, Yu L, Tang B, Liu X, Song Y, Wang X, Radu B, Boireau P, Wang F, Liu M. 2012. Regulation of cytokine expression in murine macrophages stimulated by excretory/secretory products from Trichinella spiralis in vitro. Molecular and Cellular Biochemistry, 360, 79-88.

3. Beiting DP, Gagliardo LF, Hesse M, Bliss SK, Meskill D, Appleton JA. 2007. Coordinated control of immunity to muscle stage Trichinella spiralis by IL-10, regulatory T cells, and TGFbeta. Journal of Immunology, 178, 1039-1047.

4. Bien J, Cabaj W, Moskwa B. 2015. Proteomic analysis of potential immunoreactive proteins from muscle larvae and adult worms of Trichinella spiralis in experimentally infected pigs. Folia Parasitologica, 62, 22.

5. Boer MC, Joosten SA, Ottenhoff THM. 2015. Regulatory T-cells at the interface between human host and pathogens in infectious diseases and vaccination. Frontiers in Immunology, 6, 217.

6. Bruschi F, Chiumiento L. 2011. Trichinella inflammatory myopathy: host or parasite strategy? Parasites \& Vectors, 4, 42.

7. Chen D. 2008 . TH17 cells in development: an updated view of their molecular identity and genetic programming. Nature Reviews Immunology, 8, 337-348.

8. Chu KB, Kim SS, Lee SH, Lee HS, Joo KH, Lee JH, Lee YS, Zheng S, Quan FS. 2014. Enhanced protection against 
Clonorchis sinensis induced by co-infection with Trichinella spiralis in rats. Parasite Immunology, 36, 522-530.

9. Chung F. 2001. Anti-inflammatory cytokines in asthma and allergy: interleukin-10, interleukin-12, interferon-gamma. Mediators of Inflammation, 10, 51-59.

10. Dupouy-Camet J, Murrell KD. 2008. FAO/WHO/OIE: guidelines for the surveillance, management, prevention and control of trichinellosis. HortTechnology, 177, 300.

11. Fontana MF, Baccarella A, Kellar D, Oniskey TK, Terinate P, Rosenberg SD, Huang EJ, Herbert DR, Kim CC. 2015. Myeloid expression of the AP-1 transcription factor JUNB modulates outcomes of type 1 and type 2 parasitic infections. Parasite Immunology, 37, 470-478.

12. Franssen FF, Fonville M, Takumi K, Vallee I, Grasset A, Koedam MA, Wester PW, Boireau P, van der Giessen JW. 2011. Antibody response against Trichinella spiralis in experimentally infected rats is dose dependent. Veterinary Research, 42, 113.

13. Freeman CM, Chiu BC, Stolberg VR, Hu J, Zeibecoglou K, Lukacs NW, Lira SA, Kunkel SL, Chensue SW. 2005. CCR8 is expressed by antigen-elicited, IL-10-producing CD4+CD25+ T cells, which regulate Th2-mediated granuloma formation in mice. Journal of Immunology, 174, 1962-1970.

14. Gottstein B, Pozio E, Nockler K. 2009. Epidemiology, diagnosis, treatment, and control of trichinellosis. Clinical Microbiology Reviews, 22, 127-145.

15. Gravano DM, Vignali DAA. 2012. The battle against immunopathology: infectious tolerance mediated by regulatory T cells. Cellular and Molecular Life Sciences, 69, 1997-2008.

16. Ilic N, Gruden-Movsesijan A, Sofronic-Milosavljevic L. 2012. Trichinella spiralis: shaping the immune response. Immunologic Research, 52, 111-119.

17. Lawrence CE, Paterson JC, Higgins LM, MacDonald TT, Kennedy MW, Garside P. 1998. IL-4-regulated enteropathy in an intestinal nematode infection. European Journal of Immunology, 28, 2672-2684.

18. Li CK, Ko RC. 2001. Inflammatory response during the muscle phase of Trichinella spiralis and T. pseudospiralis infections. Parasitology Research, 87, 708-714.
19. Liu RD, Wang ZQ, Wang L, Long SR, Ren HJ, Cui J. 2013. Analysis of differentially expressed genes of Trichinella spiralis larvae activated by bile and cultured with intestinal epithelial cells using real-time PCR. Parasitology Research, 112, $4113-4120$.

20. Ljungstrom I, Ferrante A. 1984. The in vivo and in vitro immunodepression by Trichinella spiralis. Trichinellosis, 6 , 63-70.

21. Luft BJ, Kim CW. 1988. T-cell dysfunction during acute murine trichinellosis. Trichinellosis, 7, 153-158.

22. Pozio E. 1989. Present knowledge of the taxonomy, distribution and biology of genera of Trichinella (Nematoda, Trichinellidae). Annali dell'Istituto Superiore di Sanità, 25, 615-623.

23. Ren HJ, Cui J, Yang W, Liu RD, Wang ZQ. 2013. Identification of differentially expressed genes of Trichinella spiralis larvae after exposure to host intestine milieu. PLoS One, 8, e67570.

24. Wang CH. 1997. Study of biological properties of Trichinella spiralis newborn larvae and the antiparasitic mucosal immunity of the host. Frontiers in Bioscience, 2, 317-330.

25. Wang J, Cui J, Wang ZQ. 2007. Serum IgG levels in the mice experimentally infected with Trichinella spp. Journal of Pathogen Biology, 2, 266-267.

26. Wang YF, Wang N, Ding J, Sun Y, Liu XL, Wang XL, Liu MY, Bai X. 2014. ML ES-treated macrophage on C2C12 myoblasts differentiation programin vitro using co-culture technique. Chinese Journal of Zoonoses, 30, 893-897.

27. Xing J, Li P, Yan WY. 2005. The dynamic observation on the immunological function of rat infected with Trichinella spiralis. Chinese Journal of Parasitic Disease Control, 18, 26-27.

28. Zhao G, Yang WT, Wang CF, Yang GL. 2013. Research progress on the mechanism of host immune response regulated by Trichinella spiralis. Chinese Journal of Parasitology and Parasitic Diseases, 6, 542-543.

29. Zocevic A, Mace P, Vallee I, Blaga R, Liu M, Lacour SA, Boireau P. 2011. Identification of Trichinella spiralis early antigens at the pre-adult and adult stages. Parasitology, 138, 463-471.

Cite this article as: Song Y, Xu J, Wang X, Yang Y, Bai X, Pang J, Wang X, Yu M, Liu M, Liu X \& Sun S. 2019. Regulation of host immune cells and cytokine production induced by Trichinella spiralis infection. Parasite 26, 74.

Reviews, articles and short notes may be submitted. Fields include, but are not limited to: general, medical and veterinary parasitology; morphology, including ultrastructure; parasite systematics, including entomology, acarology, helminthology and protistology, and molecular analyses; molecular biology and biochemistry; immunology of parasitic diseases; host-parasite relationships; ecology and life history of parasites; epidemiology; therapeutics; new diagnostic tools.

All papers in Parasite are published in English. Manuscripts should have a broad interest and must not have been published or submitted elsewhere. No limit is imposed on the length of manuscripts.

Parasite (open-access) continues Parasite (print and online editions, 1994-2012) and Annales de Parasitologie Humaine et Comparée (1923-1993) and is the official journal of the Société Française de Parasitologie. 